Article

\title{
On the Cattaneo-Christov Heat Flux Model and OHAM Analysis for Three Different Types of Nanofluids
}

\author{
Umair Khan ${ }^{1}{ }^{(1)}$, Shafiq Ahmad ${ }^{2}$, Arsalan Hayyat ${ }^{2}$, Ilyas Khan ${ }^{3, *} *$, \\ Kottakkaran Sooppy Nisar 4 (D) and Dumitru Baleanu 5,6,7 \\ 1 Department of Mathematics and Social Sciences, Sukkur IBA University, Sukkur 65200, Sindh Pakistan; \\ umairkhan@iba-suk.edu.pk \\ 2 Department of Mathematics, Quaid-I-Azam University 45320, Islamabad 44000, Pakistan; \\ ashafiq@math.qau.edu.pk (S.A.); arsalanhayyat786@gmail.com (A.H.) \\ 3 Faculty of Mathematics and Statistics, Ton Duc Thang University, Ho Chi Minh City 72915, Vietnam \\ 4 Department of Mathematics, College of Arts and Sciences, Prince Sattam bin Abdulaziz University, \\ Wadi Aldawaser 11991, Saudi Arabia; n.sooppy@psau.edu.sa \\ 5 Department of Mathematics, Cankaya University, Ankara 06530, Turkey; Baleanu@mail.cmuh.org.tw \\ 6 Institute of Space Sciences, 077125 Magurele, Romania \\ 7 Department of Medical Research, China Medical University Hospital, China Medical University, \\ Taichung 40447, Taiwan \\ * Correspondence: ilyaskhan@tdtu.edu.vn
}

Received: 23 November 2019; Accepted: 20 January 2020; Published: 29 January 2020

\begin{abstract}
In this article, the boundary layer flow of a viscous nanofluid induced by an exponentially stretching surface embedded in a permeable medium with the Cattaneo-Christov heat flux model (CCHFM) is scrutinized. We took three distinct kinds of nanoparticles, such as alumina $\left(\mathrm{Al}_{2} \mathrm{O}_{3}\right)$, titania $\left(\mathrm{TiO}_{2}\right)$ and copper $(\mathrm{Cu})$ with pure water as the base fluid. The features of the heat transfer mechanism, as well as the influence of the relaxation parameter on the present viscous nanofluid flow are discussed here thoroughly. The thermal stratification is taken in this phenomenon. First of all, the problem is simplified mathematically by utilizing feasible similarity transformations and then solved analytically through the OHAM (optimal homotopy analysis method) to get accurate analytical solutions. The change in temperature distribution and axial velocity for the selected values of the specific parameters has been graphically portrayed in figures. An important fact is observed when the thermal relaxation parameter (TRP) is increased progressively. Graphically, it is found that an intensification in this parameter results in the exhaustion of the fluid temperature together with an enhancement in the heat transfer rate. A comparative discussion is also done over the Fourier's law and Cattaneo-Christov model of heat.
\end{abstract}

Keywords: Cattaneo-Christov heat flux; porous medium; exponentially stretching surface; nanoparticle; OHAM method

\section{Introduction}

Heat transfer analysis is involved in different aspects of engineering and biomedical applications such as continuous stretching of plastic films, energy production process, drawing of copper wires, conduction of heat in tissues, hot rolling, magnetic drug targeting, nuclear reactor cooling, space cooling, metal spinning's and many other important fields. The heat transfer phenomenon arises due to the differences in the temperature between two objects or in the same object. When one considers distinct materials with distinct temperature then the flow of heat occurs from the peak temperature to the 
body at minimum temperature. Until now, Fourier's popular law [1] was used for the heat transfer mechanism. This law states that any initial change in temperature is immediately spread all through the entire medium under examination. However, in fact, no such material or object existed there, which gives the proof of Fourier's heat conduction law. To solve this problem, Cattaneo [2] proposed an adjusted Fourier's law by involving a term called the relaxation term. Thus, Christov [3] utilized the upper-convected derivative model of Oldroyd [4] to describe Cattaneo heat flux law. The physical interpretation of the heat flux Cattaneo-Christov model is that the heat transfer throughout the whole medium at a slow rate. The influences of the Cattaneo-Christov model of heat flux with initial and boundary problems and their structural stability solutions have been discussed by Tibullo and Zampoli [5]. The Cattaneo-Christov model to explore the transfer of heat for fluid with viscoelasticity enclosed by a sheet (stretching) and flow with slip is studied by Khan et al. [6]. Straughan [7] and Haddad [8] examined the law of the Cattaneo-Christov model of heat flux with thermal convection and obtained the computational solutions. Crane and Carragher [9] observed the heat transfer mechanism on a continuous shrinking surface. Later on, lots of investigations were made to consider the flow past an exponentially expanding surface. Keller and Magyari [10] inspected the flow where the viscous effects are dominant past an exponentially stretching sheet through exponential temperature profile distribution. Mustafa [11] investigated the spinning flow of viscoelastic fluids due to a stretching sheet by employing the Cattaneo-Christov heat flux model (CCHFM). Khan [12] studies the heat transfer mechanism and three dimensions Burgers liquid flow by assuming the model of heat flux called Cattaneo-Christov.

The phenomenon of heat transport over a stretchable surface is a broad field of new thinking and idea in the current time. Some key fluid velocity problems for the diverse liquid flow for exponential stretchable sheet are obtainable [13-15]. Partha et al. [16] initiated the fluid flow in more than one dimension, which is induced by an exponentially stretching sheet with the combined impacts of mixed convection and viscous dissipation. Nadeem et al. [17] scrutinized the transfer rate of heat and the boundary layer fluid flow of a Maxwell fluid past exponentially stretching. In recent time, the main focus on the subject of various examinations, which is the flow through a permeable source. The survey has been animated in this field, to a degree, which is the expansive one and by the fact that in various discipline engineering, physics, applied mathematics and industries they have various applications of the heat transfer motivated fluid flows in permeable source types media like fibrous insulations and the ground dumping of non-atomic or atomic waste, earth science systems, etc. A comprehensive review of the literature can be seen in the books by Pop and Ingham [18] and Vafai [19]. The magnetohydrodynamic (MHD) two-dimensional boundary layer flows of a Maxwell fluid, which is upper-convected were investigated in [20,21] for porous objects. Further, Lesnic et al. [22,23] combined the natural convection via the theory of boundary layer and the Newtonian heating $(\mathrm{NH})$ past a slope zero and a sheet vertically saturated in permeable media. Aliakbar et al. [24] showed the results of different embedded arbitrary constants on the temperature profile above the sheet. Nadeem et al. [25] considered the transfer of heat phenomenon past an exponentially stretching sheet with Newtonian heating.

Nanofluid are fluids that are taken to be in a nanosize arrangement. These liquids are a mixture of nanoparticles i.e., (carbon nanotubes or carbides, oxides and metal) and base liquids (including glycol, ethylene, oil, water, etc.). We called these types of liquid a nanofluid and were familiarized by Choi [26]. These liquids having a much-augmented conductivity for the escalating thermal performance. Eastman et al. [27] examined that boost up the thermal conductivity depends upon the body, shape and thermal properties of the nanoparticles. Nanoparticles are the important features of the rapidly developing field of nanotechnology. Their uniqueness and existence properties make these particles vital and major in many fields of human action. This review tries to abridge the short and the latest advancements in the field of applied nanoparticles, specifically, their application in medicine, chemistry and biology and many other fields of education like science and technology. Nadeem et al. [28] considered the nonlinear stretching sheet to explored the feature of heat transfer in the presence of three 
different nanoparticles, such as $\mathrm{Cu}, \mathrm{Al}_{2} \mathrm{O}_{3}$, and $\mathrm{TiO}_{2}$. Khan et al. [29] examined the three-dimensional unsteady CNTs nanofluid flow in the existence of velocity and thermal slip. Recently many researchers investigated the influence of different nanoparticle in various flow fields [30-35].

Analytical solutions have great importance in physical problems. The analysis of OHAM is functional to solve the formulated boundary value problem and obtained analytical results. Liao [36,37] suggested the homotopy analysis method and optimal HAM approach to get analytical solutions for non-linear differential equations. Other interesting related numerical investigations can be found in [38-49].

In this work, we applied the Cattaneo-Christov model of heat flux to study the boundary layer flow of a viscous nanofluid induced by an exponentially stretching surface embedded in a porous medium. The guess of thermal stratification is to be invoked. The given problem is mathematically constructed and their dimensionless ordinary differential equations (ODEs) are computed by exercising the appropriate transformations and then obtain the exact solutions through OHAM (optimal homotopy analysis method). The differences in the fluid flow movement for the two fields of velocity and the temperature for diverse approximations of relevant interesting parameters of aforementioned nanofluids have been explained graphically. Stress is given to the fact that augmentation in the thermal relaxation parameter shows interesting exhaustion in the field of temperature distribution and the rate of heat transfer advancements.

\section{Problem Formulation}

Let us take the steady two-dimensional boundary layer flow of an incompressible viscous nanofluid past an exponentially stretching sheet flooded in a permeable medium. Utilizing the boundary layer estimates the governing equations for the flow problem are obtained as

$$
\begin{gathered}
\frac{\partial u}{\partial x}+\frac{\partial v}{\partial y}=0 \\
\rho_{n f}\left(u \frac{\partial u}{\partial x}+v \frac{\partial v}{\partial y}\right)+\frac{\partial p}{\partial x}-\mu_{n f} \frac{\partial^{2} u}{\partial y^{2}}=-\frac{\mu_{n f} \varepsilon}{K} u .
\end{gathered}
$$

In the aforementioned equations, $u$ and $v$ represent the velocity components along with the $x$ and $y$ directions respectively, $\varepsilon$ indicates the porosity of the medium and $K$ is regarded as the permeability of the fluidic medium. The parameters $\mu_{n f}$ (nanofluid viscosity) and $\rho_{n f}$ (nanofluid density) are defined below by

$$
\mu_{n f}=\frac{\mu_{f}}{(1-\phi)^{2.5}}, \rho_{n f}=(1-\phi) \rho_{f}+\phi \rho_{s} .
$$

Here $\phi$ indicates the nanoparticles volume fraction of nanofluid, $\rho_{f}$ denotes the fluid density of the base fluid, $\rho_{s}$ specifies nanoparticles density and $\mu_{f}$ represents base fluid viscosity. For the steady boundary layer flow, the equation of energy is

$$
-\mathbf{V} . \nabla T=\frac{\nabla \cdot \mathbf{q}}{\left(\rho c_{p}\right)_{n f}},
$$

where $\left(\rho c_{p}\right)_{n f}$ signifies specific heat capacity of nanofluid, $T$ demonstrates local fluid temperature and $q$ represents heat flux satisfying Cattaneo-Christov heat flux law given below

$$
\mathbf{q}+\lambda_{2}\left[\frac{\partial \mathbf{q}}{\partial t}+(\nabla \cdot \mathbf{V}) \mathbf{q}-\mathbf{q} \cdot \nabla \mathbf{V}+\mathbf{V} \cdot \nabla \mathbf{q}\right]=-k_{n f} \nabla T
$$


in which $\lambda_{2}$ indicates thermal relaxation time, $\mathbf{V}$ denotes the velocity vector and $k_{n f}$ represents the thermal conductivity of the nanofluid. Using the fact that fluid is incompressible and utilizing Equation (5) in Equation (4), the temperature equation takes the form

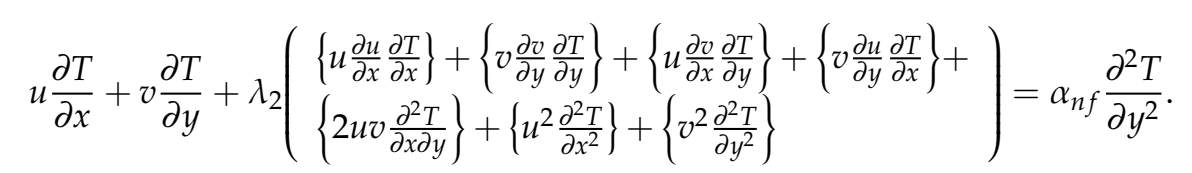

Here, the parameter $\alpha_{n f}$ denotes the thermal diffusivity of nanofluid defined as follow

$$
\begin{gathered}
\alpha_{n f}\left(\rho c_{p}\right)_{n f}=k_{n f},\left(\rho c_{p}\right)_{n f}-(1-\phi)\left(\rho c_{p}\right)_{f}=\phi\left(\rho c_{p}\right)_{s^{\prime}} \\
\frac{k_{n f}}{k_{f}}=\frac{\left(2 k_{f}+k_{s}\right)-2 \phi\left(k_{f}-k_{s}\right)}{\left(2 k_{f}+k_{s}\right)+\phi\left(k_{f}-k_{s}\right)}, \quad v_{n f} \rho_{n f}=\mu_{n f} .
\end{gathered}
$$

Here $k_{f}$ indicates the thermal conductivity of base fluid whereas $k_{s}$ indicates solid thermal conductivity. The associated boundary conditions are imposed as below

$$
\begin{aligned}
& \left.v\right|_{y=0}=0,\left.u\right|_{y=0}=U_{w}(x)=U_{0} e^{(x / l)},\left.T\right|_{y=0}=T_{w}(x)=T_{0}+a e^{(x / l)}, \\
& \left.u\right|_{y \rightarrow \infty} \rightarrow 0,\left.T\right|_{y \rightarrow \infty} \rightarrow T_{\infty}=T_{0}+b e^{(x / l)}
\end{aligned}
$$

Here $U_{w}(x)$ denotes the velocity of the stretching surface, $U_{0}$ identifies the reference velocity, $l$ signifies a characteristic length, $(a, b)$ are dimensional constants, $T_{w}(x)$ and $T_{\infty}$ represent the wall and ambient temperature or far away temperature, respectively.

The geometrical structure of the problem is given in Figure 1.

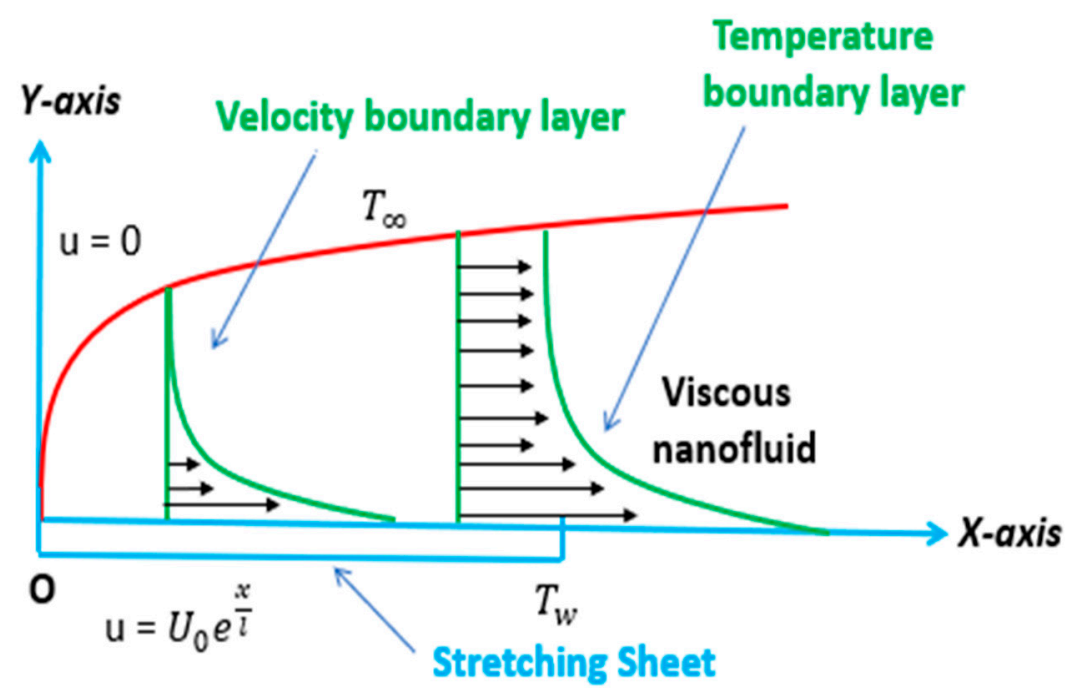

Figure 1. Physical diagram of the present flow model.

The problem considered here is based on the following suitable similarity transformations $[13,17,25]$.

$$
\begin{aligned}
& \eta=\sqrt{\frac{U_{0}}{2 v l}} e^{(x / 2 l)} y, u=U_{0} e^{(x / l)} f^{\prime}(\eta), \\
& v=-\sqrt{\frac{v U_{0}}{2 l}} e^{(x / 2 l)}\left\{\eta f^{\prime}+f\right\}, \theta(\eta)=\frac{T-T_{\infty}}{T_{w_{w}}-T_{0}} .
\end{aligned}
$$

Equation (1) is equivalently satisfied and Equations (2)-(8) are transformed into the following form

$$
\frac{1}{(1-\phi)^{2.5}\left(1-\phi+\phi\left(\rho_{s} / \rho_{f}\right)\right)} f^{\prime \prime \prime}+f f^{\prime \prime}-2\left(f^{\prime}\right)^{2}-\frac{2 P_{m}}{\left(1-\phi+\phi\left(\rho_{s} / \rho_{f}\right)\right)} f^{\prime}=0
$$




$$
\begin{gathered}
\frac{1}{\operatorname{Pr}} \frac{k_{n f} / k_{f}}{\left(1-\phi+\phi\left(\rho c_{p}\right)_{s} /\left(\rho c_{p}\right)_{f}\right)} \theta^{\prime \prime}+\theta^{\prime} f-\frac{1}{2} \lambda_{t}\left(f^{2} \theta^{\prime \prime}-f f^{\prime} \theta^{\prime}\right)=0, \\
f^{\prime}(\eta)=1, f(\eta)=0, \theta(\eta)=1-S \text { at } \eta=0, \\
f^{\prime}(\eta) \rightarrow 0, \theta(\eta) \rightarrow 0 \text { as } \eta \rightarrow \infty .
\end{gathered}
$$

In the above equations, the embedded parameters thermal stratification (TS) is denoted by $S$, the porous medium parameter (PMP) is designated by $P_{m}$, the Prandtl number (PN) is symbolized by $\operatorname{Pr}$ and the non-dimensional thermal relaxation time (TRT) is represented by $\lambda_{t}$. These physical parameters are defined as

$$
P_{m}=\frac{v \varepsilon}{U_{0} K}, \operatorname{Pr}=v / \alpha, \lambda_{t}=\lambda_{2} U_{0}, S=b / a .
$$

Note that for $\lambda_{t}=0$ leads to the classical Fourier's heat conduction law.

\section{Variables of Engineering Interest}

The physical quantity such as the shear stress rate (local coefficient of skin friction) is given by

$$
C_{f}=\frac{\tau_{w}}{\rho_{f} U_{\infty}^{2}}, \tau_{w}=\mu_{n f}\left(\frac{\partial u}{\partial y}\right)_{y=0} .
$$

Consuming the similarity transformation (9) the above equation becomes

$$
\sqrt{\operatorname{Re}_{x}} C_{f}=\frac{1}{(1-\phi)^{2.5}} f^{\prime \prime}(0) .
$$

By making use of Equation (15), extensive data results are outputted in Table 1 for reduced skin friction coefficient $\sqrt{\operatorname{Re}_{x}} C_{f}$. However the values specified to the parameters $\phi, P_{m}$ and $\lambda_{t}$, it is found that the nanoparticles $\mathrm{TiO}_{2}$ exhibit higher frictional effect that the other nanoparticles.

Table 1. Numerical data set for skin friction of three different types of water-base nanofluids.

\begin{tabular}{cccccc}
\hline \multirow{2}{*}{$\phi$} & \multirow{2}{*}{$\boldsymbol{P}_{m}$} & $\lambda_{t}$ & \multicolumn{3}{c}{$\sqrt{\mathrm{Re}_{x}} C_{f}$} \\
\cline { 4 - 6 } & & & $\mathbf{C u}$ & $\mathbf{A l}_{2} \mathbf{O}_{3}$ & $\mathbf{T i O}_{2}$ \\
\hline 0.01 & & & 1.3228 & 1.4760 & 1.5230 \\
0.03 & 0.1 & 0.3 & 1.6384 & 1.7334 & 1.8384 \\
0.05 & & & 1.8550 & 2.0755 & 2.2550 \\
& 0.2 & & 1.3230 & 1.3759 & 1.4229 \\
0.05 & 0.4 & 0.3 & 1.5307 & 1.5898 & 1.6306 \\
& 0.6 & & 1.7151 & 1.7785 & 1.8150 \\
& & 0.1 & 1.3312 & 1.4211 & 1.5311 \\
0.05 & 0.6 & 0.2 & 1.3312 & 1.4212 & 1.5312 \\
& & 0.4 & 1.3312 & 1.4212 & 1.5312 \\
\hline
\end{tabular}

\section{Optimal Homotopy Analysis Method (OHAM)}

The initial estimates and linear operators for optimal HAM results are

$$
\begin{gathered}
f_{0}(\eta)=\left(1-e^{(-\eta)}\right), \theta_{0}(\eta)=(1-S) e^{(-\eta)}, \\
L_{f}(f)+\frac{d f}{d \eta}-\frac{d^{3} f}{d \eta^{3}}=0, L_{\theta}(\theta)+\theta-\frac{d^{2} \theta}{d \eta^{2}}=0 .
\end{gathered}
$$

Here linear operators are denoted by $L_{f}(f)$ and $L_{\theta}(\theta)$, whereas the initial guesses of the functions $\{f(\eta), \theta(\eta)\}$ are represented by $\left\{f_{0}(\eta), \theta_{0}(\eta)\right\}$. 


\section{Convergence Analysis}

We utilized the optimal homotopy analysis techniques to alter and control the resulting convergence series results. Suitable values are assigned to auxiliary parameters $\left\{h_{f}, h_{\theta}\right\}$ to get the convergent solutions. The errors residual are obtained for velocity and temperature equations by expressions defined below.

$$
\begin{aligned}
& \Delta_{m}{ }^{f}=\int_{0}^{1}\left[R_{m}{ }^{f}\left(\eta, h_{f}\right)\right]^{2} d \eta, \\
& \Delta_{m}{ }^{\theta}=\int_{0}^{1}\left[R_{m}{ }^{\theta}\left(\eta, h_{\theta}\right)\right]^{2} d \eta .
\end{aligned}
$$

The parametric values convergence exercising by utilizing the procedure OHAM, which is enumerated below in Tables 2 and 3. The values assigned to residual parameters are $\operatorname{Pr}=6.2, S=0.8$, $P m=0.5, \lambda=1$.

Table 2. Average residual square errors $\left(\varepsilon_{m}^{t}\right)$.

\begin{tabular}{cccc}
\hline$\frac{\text { values } \rightarrow}{\text { order } \downarrow}$ & $h_{f}$ & $h_{\theta}$ & $\varepsilon_{m}^{t}$ \\
\hline 8 & -0.573983 & -0.918049 & $6.98675 \times 10^{-6}$ \\
10 & -0.565917 & -0.931985 & $9.05515 \times 10^{-7}$ \\
12 & -0.539285 & -1.38686 & $1.45651 \times 10^{-8}$ \\
14 & -0.535106 & -1.37685 & $2.06408 \times 10^{-9}$ \\
16 & -0.531844 & -1.36636 & $3.99551 \times 10^{-10}$ \\
\hline
\end{tabular}

Table 3. Discrete residual square errors for $\varepsilon_{m}^{f}$ and $\varepsilon_{m}^{\theta}$

\begin{tabular}{ccc}
\hline$\frac{\text { values } \rightarrow}{\text { order } \downarrow}$ & $h_{f}=-0.570464$ & $h_{\theta}=-1.23274$ \\
& $\varepsilon_{m}^{f}$ & $\varepsilon_{m}^{\theta}$ \\
4 & $1.72569 \times 10^{-6}$ & 0.000020310 \\
8 & $2.87068 \times 10^{-9}$ & $5.78132 \times 10^{-7}$ \\
12 & $9.29003 \times 10^{-12}$ & $1.7193 \times 10^{-11}$ \\
20 & $2.74651 \times 10^{-15}$ & $6.16398 \times 10^{-15}$ \\
\hline
\end{tabular}

The graphical picture for 8th and 10th order approximations show the error decline in the subsequent figures (Figures 2 and 3 ).

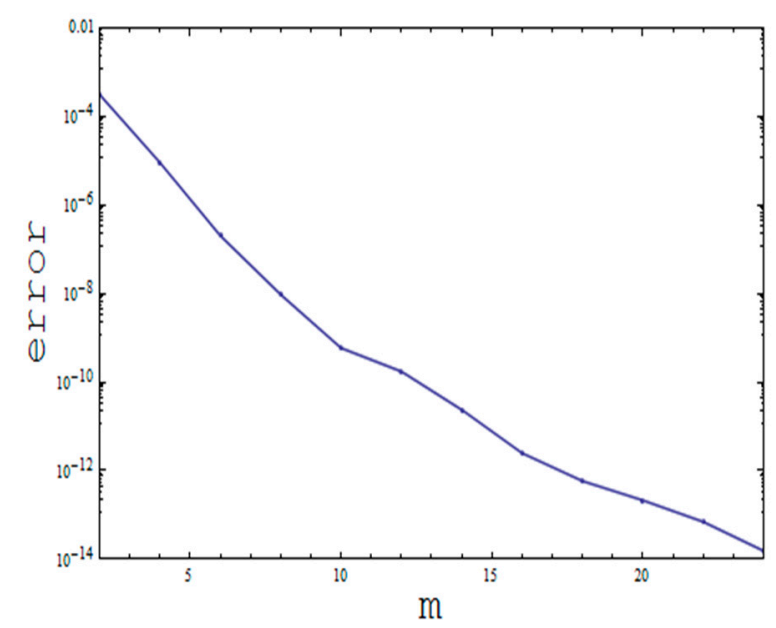

Figure 2. Results of 8th order approximations. 


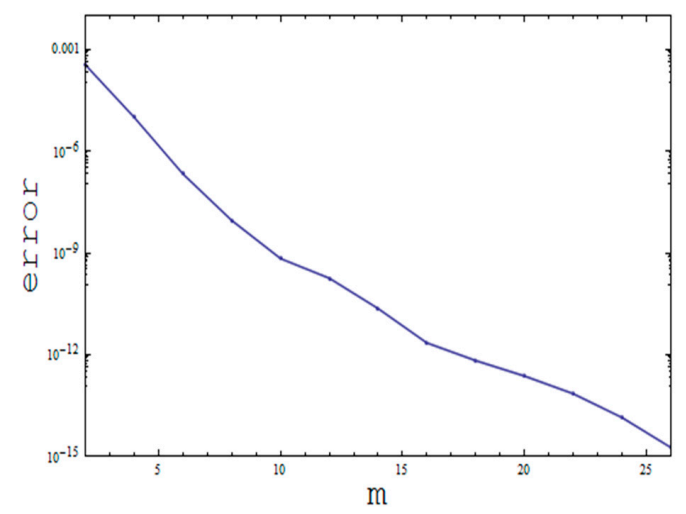

Figure 3. Results of 10th order approximations.

Here, the quantity $\varepsilon_{m}^{t}\left(=\varepsilon_{m}^{f}+\varepsilon_{m}^{\theta}\right)$ represents the total squared of the residual error, which is utilized to achieve the control parameters for the convergence of the optimal solution.

\section{Results and Discussion}

The physical impacts of the miscellaneous emerging parameters containing nanoparticles volume fraction $(0 \leq \phi \leq 0.3)$, porosity parameter $\left(0.2 \leq P_{m} \leq 0.8\right)$, thermal stratification $(0 \leq S \leq 0.4)$, of the dimensionless thermal relaxation time $\left(0 \leq \lambda_{t} \leq 4\right)$ on the axial velocity and the distribution of temperature were well explained in this part. Note that in all these graphs and tables, the value of Prandtl number ( $P r)$ was kept fixed, i.e., $\operatorname{Pr}=6.2$ for the base fluid water. Graphical results are portrayed in Figures 4-12.

\subsection{The Impact of the Parameter $P_{m}$ (Called Porosity Parameter)}

In this subclass, we discussed the behavior of $P_{m}$ (non-dimension porosity parameter) on velocity and temperature profiles. Figure 4 shows the effect of $P_{m}$ on the behavior of axial velocity. As expected, the reduction in the velocity distribution was seen with an augmentation in the estimation of $P_{m}$. Further, the flow profile of velocity was higher in the absence of solid volume fraction parameter $\phi$. Figure 5 displays that due to the enhancement in the value of $P_{m}$ (porosity parameter), the dimensionless temperature profile increased. Physically, it happened due to the decrease in the permeability $K$ of the permeable source and the fluid effective viscosity. Notably, the variation in the temperature $\theta$ for $\lambda_{t}=0.5$ was lower as compared to $\lambda_{t}=0$.

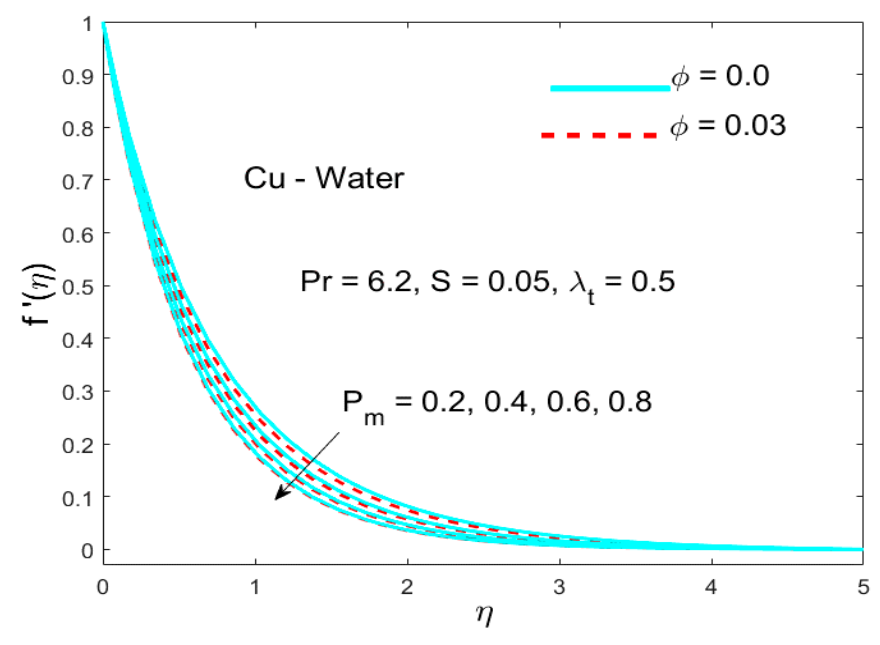

Figure 4. Influence of $P_{m}$ on the axial velocity. 


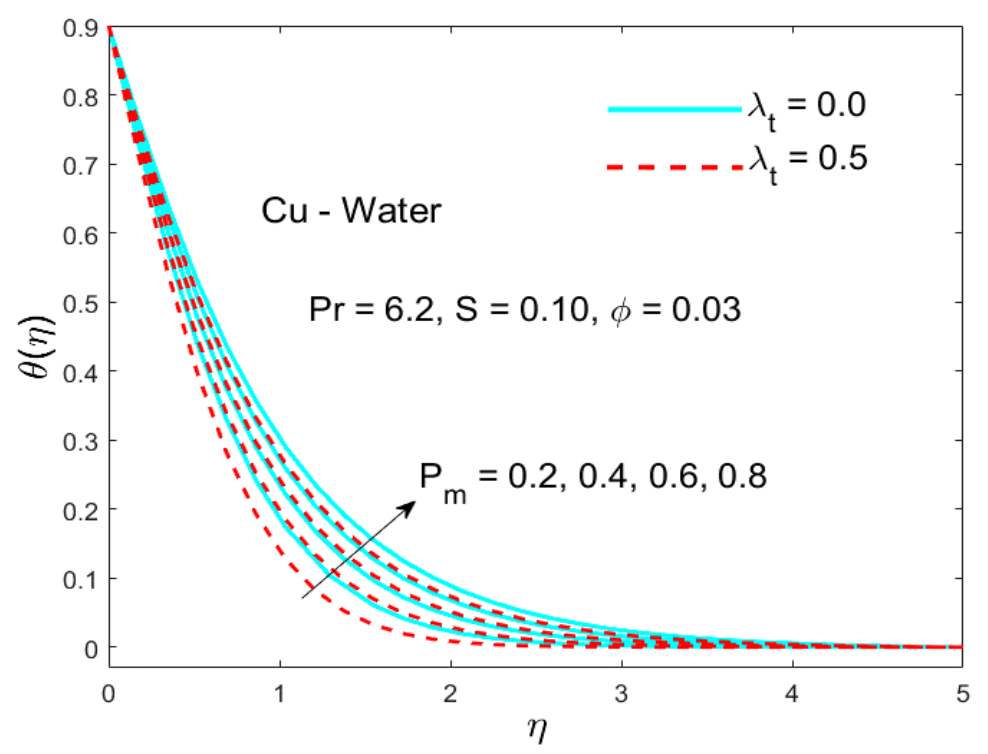

Figure 5. Effect of $P_{m}$ on the temperature field.

\subsection{The Impact of the Parameter S (Thermal Stratification)}

Figure 6 portrays the stimulus of parameter $S$, i.e., TSP on the field of temperature. Here it is fascinating to note that the enrichment in the values of the thermal stratified parameter $S$ caused the temperature distribution to become thinner. Physically, this is on the grounds that reasonably temperature differences decrease between the surrounding and surface of the sheet, and this fact reduces the fluid temperature.

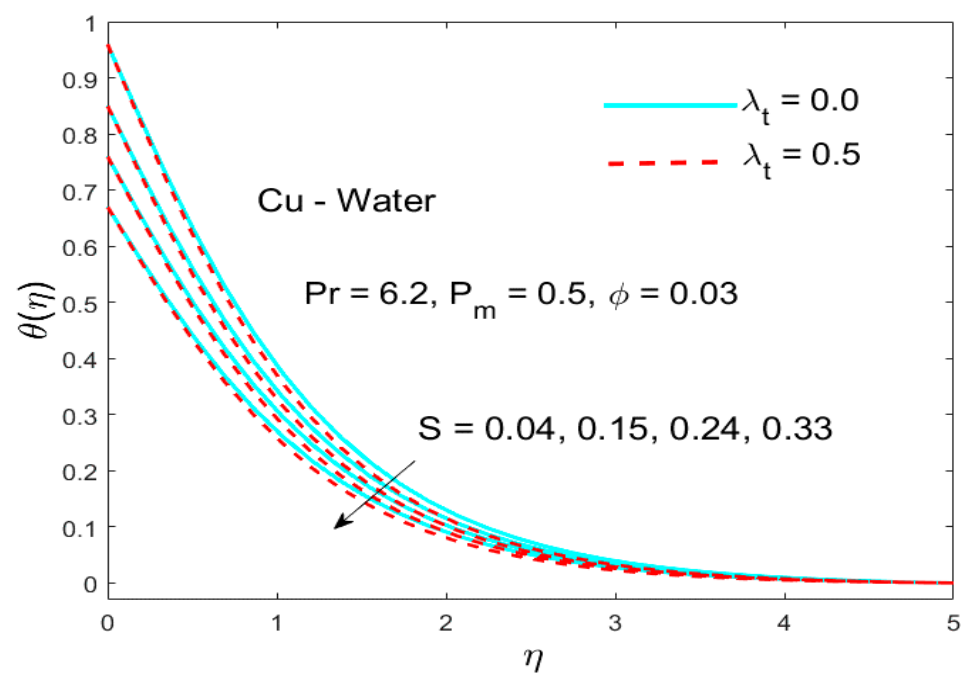

Figure 6. Temperature profiles for different values of $S$.

\subsection{The Influence of the Parameter $\lambda_{t}$ Called (Thermal Relaxation)}

The characteristics of the dimensionless thermal relaxation parameter $\lambda_{t}$ on $\theta(\eta)$ are revealed in Figure 7 . The temperature distribution and the thickness of the thermal boundary layer were reduced for the greater values of $\lambda_{t}$. The physical interpretation is that the physical object like particles need more additional time to transfer heat to its nearest particles as we enhanced the value of $\lambda_{t}$. Further, we could state that for larger $\lambda_{t}$, the material demonstrated a non-conducting behavior, due to this reason the temperature distribution reduced. Fourier's heat conduction law and the Cattaneo-Christov model of heat flux comparison are elaborated in Figure 8. It is observed that for $\lambda_{t}=0$, heat transferred 
sharply all the way through the material. The worth mentioning point is that the temperature got larger for $\lambda_{t}=0$, i.e., for Fourier's law than the Cattaneo-Christov model law but qualitatively similar in both cases.

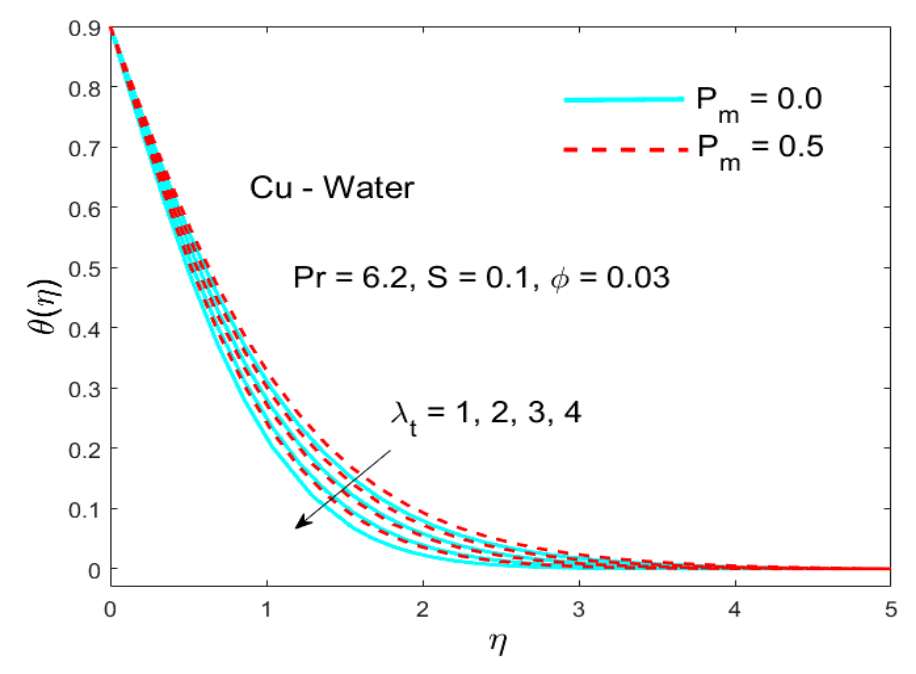

Figure 7. Effect of $\lambda_{t}$ on temperature field.

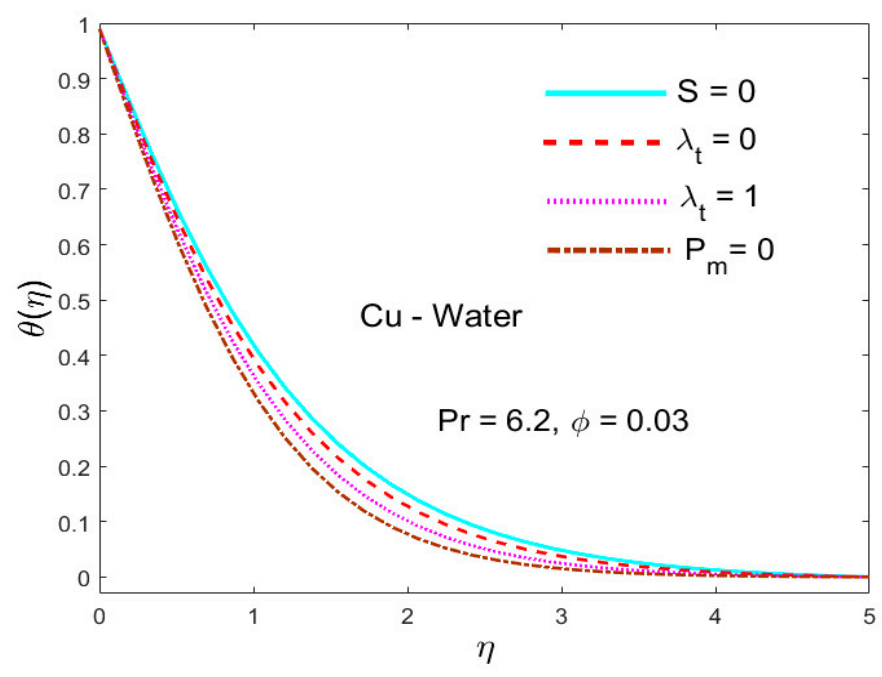

Figure 8. Effect of $\lambda_{t}, S$ and $P_{m}$ on temperature field.

\subsection{The Stimulus of the Parameter $\phi$ (Nanoparticle Volume Fraction)}

Using the thermophysical characteristics of nanoparticles and base liquid is mentioned in Table 4 . The influence of developing parameters on the flow of fluid motion and temperature was carried out through graphs and tables. The impact of the volume fraction of $\mathrm{Cu}$-water nanofluid on the velocity field is sketched in Figure 9. The enhancement in the volume fraction of $\mathrm{Cu}$-water nanofluid tended to reduce the dimensionless velocity profile. Figure 10 shows that the expansion of $\mathrm{Cu}$-nanoparticles in liquid, the opposite force to the flow of motion was advanced as compared to titanium dioxide and alumina. From Figure 11, we observed that the larger value of Cu-nanoparticles volume fraction shows an increasing trend in the temperature profile. Figure 12. illustrates the influence of the three changed water-base nanofluids such as alumina $\left(\mathrm{Al}_{2} \mathrm{O}_{3}\right)$, titanium dioxide $\left(\mathrm{TiO}_{2}\right)$ and copper $(\mathrm{Cu})$ on the non-dimensional temperature profiles. On the other hand, clearly observed that the $\mathrm{Cu}$-water nanofluids had the highest temperature profile in comparison with $\mathrm{Al}_{2} \mathrm{O}_{3}$ (alumina) and $\mathrm{TiO}_{2}$ (titanium dioxide) nanofluids. 


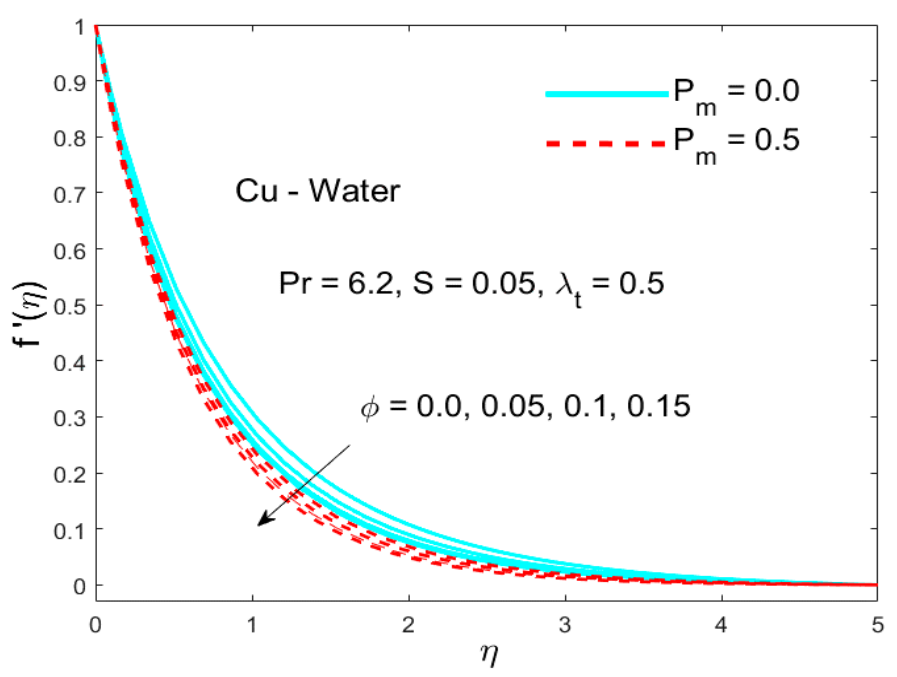

Figure 9. Effect of $\phi$ on the axial velocity.

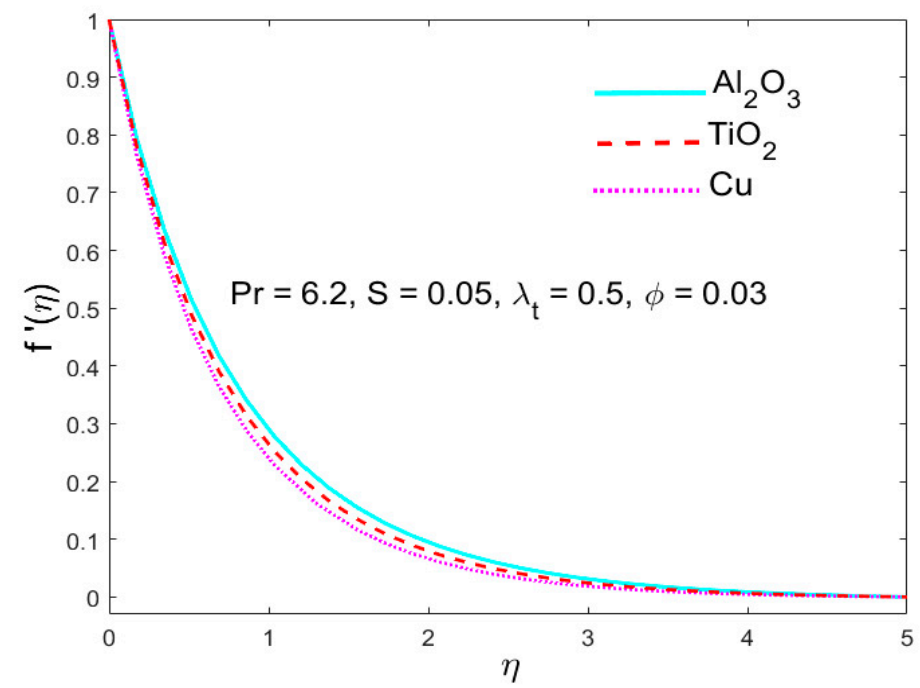

Figure 10. Effect of different nanoparticles on the velocity profile.

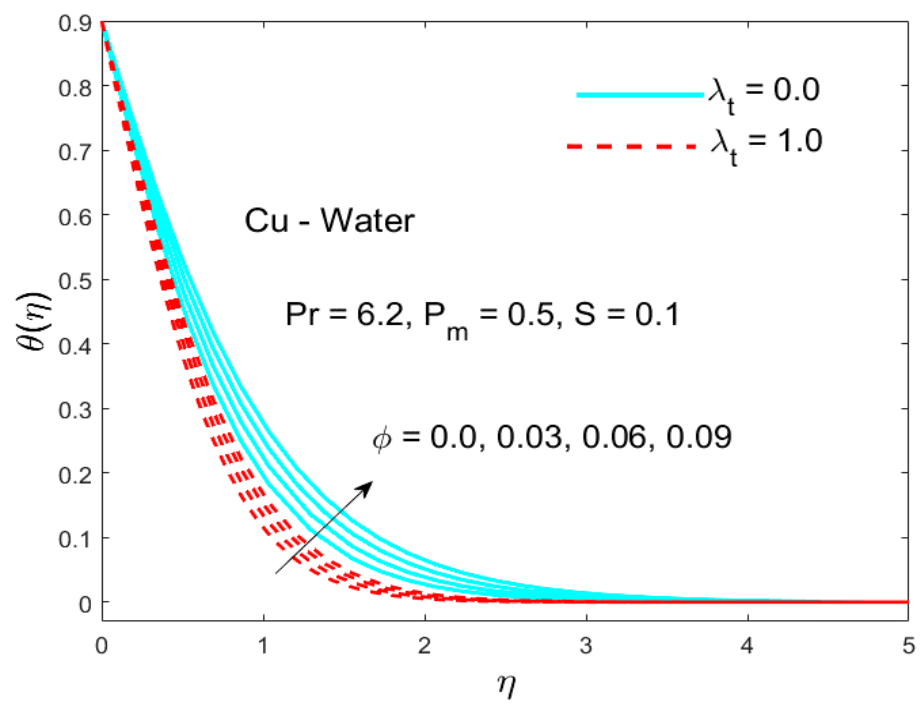

Figure 11. Variation of $C u$ nanoparticles on $\theta(\eta)$. 


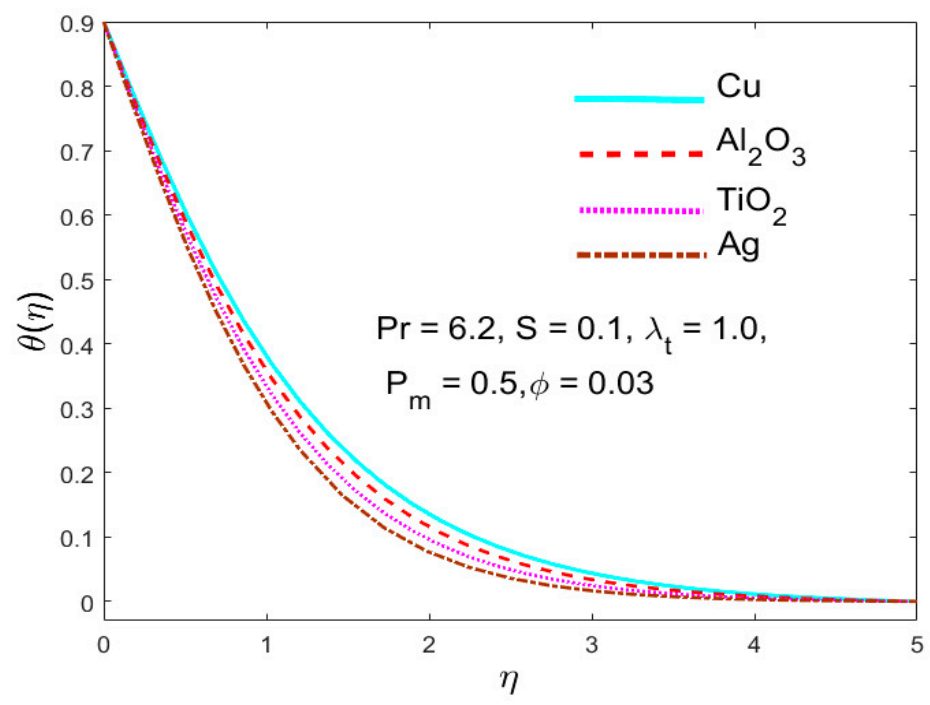

Figure 12. Effect of different nanoparticles on $\theta(\eta)$.

Table 4. Thermophysical key properties of the nanoparticles and the water (base fluid).

\begin{tabular}{ccccc}
\hline Physical Properties & $\mathbf{H}_{\mathbf{2}} \mathbf{O}$ & $\mathbf{C u}$ & $\mathbf{A l}_{\mathbf{2}} \mathbf{O}_{\mathbf{3}}$ & $\mathbf{T i O}_{\mathbf{2}}$ \\
\hline$c_{p}(\mathrm{~J} / \mathrm{kg} \mathrm{K})$ & 4179 & 385 & 765 & 686.2 \\
$\rho\left(\mathrm{kg} / \mathrm{m}^{3}\right)$ & 997 & 8933 & 3970 & 4250 \\
$\mathrm{k}(\mathrm{W} / \mathrm{m} \mathrm{K})$ & 0.613 & 400 & 40 & 8.9538 \\
\hline
\end{tabular}

\section{Concluding Remarks}

In this final section, we scrutinized the key features of the Cattaneo-Christov model of heat flux to highlight the transfer heat of viscous fluid in the existence of nanoparticles with porous media. The motion of the liquid is produced by an exponentially exercising the stretching surface. The worth mentioning remarks of the above work are summarized below.

$>$ The enhancement in the porosity parameter $P_{m}$ shows a decreasing trend in the velocity profile.

$>$ Both the temperature field and its associated layer thickness were condensed for bigger values of the thermal stratification parameter $S$.

$>$ A larger thermal relaxation parameter $\lambda_{t}$ reduced the temperature field and corresponding boundary layer thickness.

$>$ The effect of the thermal relaxation parameter was qualitatively identical in both the Cattaneo-Christov model of heat flux and Fourier models.

$>$ For nanofluids with copper nanoparticles, the velocity components show a decreasing behavior as the volume fraction of nanoparticle rose along with the saddle and nodal points.

$>$ For Cu-nanoparticles expansion in liquid, the resistance to the motion of the liquid (along $\mathrm{x}$ - and $\mathrm{y}$-axes) was found to be higher as compared to titanium dioxide $\left(\mathrm{TiO}_{2}\right)$ and alumina $\left(\mathrm{Al}_{2} \mathrm{O}_{3}\right)$.

$>$ The temperature also improved for the $\mathrm{Cu}$-water nanofluid with the increment in the volume fraction of the nanoparticles.

Author Contributions: Conceptualization, A.H. and K.S.N.; Data curation, U.K. and D.B.; Formal analysis, U.K. and S.A.; Investigation, S.A. and D.B., A.H. and I.K.; Methodology, U.K.; Project administration, A.H.; Resources, S.A.; Software, I.K. and K.S.N.; Supervision, I.K. and D.B. All authors have read and agreed to the published version of the manuscript.

Funding: This research received no external funding.

Conflicts of Interest: The authors declare no conflict of interest 


\section{References}

1. Baptiste, J.; Fourier, J. Theorie Analytique de La Chaleur; F. Didot: Paris, France, 1822.

2. Cattaneo, C. Sulla conduzione del calore. Atti Sem. Mat. Fis. Univ. Modena 1948, 3, 83-101.

3. Christov, C.I. On frame indifferent formulation of the Maxwell-Cattaneo model of finite-speed heat conduction. Mech. Res. Commun. 2009, 36, 481-486. [CrossRef]

4. Oldroyd, J.G. On the formulation of rheological equations of state. Proc. R. Soc. Lond. Ser. A Math. Phys. Sci. 1950, 200, 523-541.

5. Tibullo, V.; Zampoli, V. A uniqueness result for the Cattaneo-Christov heat conduction model applied to incompressible fluids. Mech. Res. Commun. 2011, 38, 77-79. [CrossRef]

6. Han, S.; Zheng, L.; Li, C.; Zhang, X. Coupled flow and heat transfer in viscoelastic fluid with Cattaneo-Christov heat flux model. Appl. Math. Lett. 2014, 38, 87-93. [CrossRef]

7. Straughan, B. Thermal convection with the Cattaneo-Christov model. Int. J. Heat Mass Transf. 2010, 53, 95-98. [CrossRef]

8. Haddad, S.A.M. Thermal instability in Brinkman porous media with Cattaneo-Christov heat flux. Int. J. Heat Mass Transf. 2014, 68, 659-668. [CrossRef]

9. Carragher, P.; Crane, L.J. Heat transfer on a continuous stretching sheet. ZAMM J. Appl. Math. Mech. Z. Angew. Math. Mech. 1982, 62, 564-565. [CrossRef]

10. Magyari, E.; Keller, B. Heat and mass transfer in the boundary layers on an exponentially stretching continuous surface. J. Phys. D Appl. Phys. 1999, 32, 577. [CrossRef]

11. Mustafa, M. Cattaneo-Christov heat flux model for rotating flow and heat transfer of upper convected Maxwell fluid. AIP Adv. 2015, 5, 047109. [CrossRef]

12. Khan, M.; Khan, W.A. Three-dimensional flow and heat transfer to burgers fluid using Cattaneo-Christov heat flux model. J. Mol. Liq. 2016, 221, 651-657. [CrossRef]

13. Nadeem, S.; Haq, R.U.; Lee, C. MHD flow of a Casson fluid over an exponentially shrinking sheet. Sci. Iran. 2012, 19, 1550-1553. [CrossRef]

14. Nadeem, S.; Haq, R.U.; Akbar, N.S.; Khan, Z.H. MHD three-dimensional Casson fluid flow past a porous linearly stretching sheet. Alex. Eng. J. 2013, 52, 577-582. [CrossRef]

15. Muhammad, N.; Nadeem, S.; Haq, R.U. Heat transport phenomenon in the ferromagnetic fluid over a stretching sheet with thermal stratification. Results Phys. 2017, 7, 854-861. [CrossRef]

16. Partha, M.K.; Murthy, P.V.S.N.; Rajasekhar, G.P. Effect of viscous dissipation on the mixed convection heat transfer from an exponentially stretching surface. Heat Mass Transf. 2005, 41, 360-366. [CrossRef]

17. Nadeem, S.; Ahmad, S.; Muhammad, N.; Mustafa, M.T. Chemically reactive species in the flow of a Maxwell fluid. Results Phys. 2017, 7, 2607-2613. [CrossRef]

18. Pop, I.; Ingham, D.B. Convective Heat Transfer: Mathematical and Computational Modelling of Viscous Fluids and Porous Media; Elsevier: Amsterdam, The Netherlands, 2001.

19. Vafai, K. (Ed.) Porous Media: Applications in Biological Systems and Biotechnology; CRC Press: Boca Raton, FL, USA, 2010.

20. Alizadeh-Pahlavan, A.; Aliakbar, V.; Vakili-Farahani, F.; Sadeghy, K. MHD flows of UCM fluids above porous stretching sheets using two-auxiliary-parameter homotopy analysis method. Commun. Nonlinear Sci. Numer. Simul. 2009, 14, 473-488. [CrossRef]

21. Raftari, B.; Yildirim, A. The application of homotopy perturbation method for MHD flows of UCM fluids above porous stretching sheets. Comput. Math. Appl. 2010, 59, 3328-3337. [CrossRef]

22. Lesnic, D.; Ingham, D.B.; Pop, I.; Storr, C. Free convection boundary-layer flow above a nearly horizontal surface in a porous medium with Newtonian heating. Heat Mass Transf. 2004, 40, 665-672. [CrossRef]

23. Lesnic, D.; Ingham, D.B.; Pop, I. Free convection boundary-layer flow along a vertical surface in a porous medium with Newtonian heating. Int. J. Heat Mass Transf. 1999, 42, 2621-2627. [CrossRef]

24. Aliakbar, V.; Alizadeh-Pahlavan, A.; Sadeghy, K. The influence of thermal radiation on MHD flow of Maxwellian fluids above stretching sheets. Commun. Nonlinear Sci. Numer. Simul. 2009, 14, 779-794. [CrossRef]

25. Nadeem, S.; Ahmad, S.; Muhammad, N. Cattaneo-Christov flux in the flow of a viscoelastic fluid in the presence of Newtonian heating. J. Mol. Liq. 2017, 237, 180-184. [CrossRef] 
26. Choi, S.U.; Eastman, J.A. Enhancing Thermal Conductivity of Fluids with Nanoparticles; Argonne National Lab.: Lemont, IL, USA, 1995; No. ANL/MSD/CP-84938; CONF-951135-29.

27. Eastman, J.A.; Choi, S.U.S.; Li, S.; Yu, W.; Thompson, L.J. Anomalously increased effective thermal conductivities of ethylene glycol-based nanofluids containing copper nanoparticles. Appl. Phys. Lett. 2001, 78, 718-720. [CrossRef]

28. Nadeem, S.; Ahmad, S.; Muhammad, N. Computational study of Falkner-Skan problem for a static and moving wedge. Sens. Actuators B Chem. 2018, 263, 69-76. [CrossRef]

29. Khan, U.; Ahmad, S.; Ramzan, M.; Suleman, M.; Lu, D.; Inam, S. Numerical Simulation of Darcy-Forchheimer 3D Unsteady Nanofluid Flow Comprising Carbon Nanotubes with Cattaneo-Christov Heat Flux and Velocity and Thermal Slip Conditions. Processes 2019, 7, 687.

30. Khan, U.; Zaib, A.; Khan, I.; Nisar, K.S. Activation energy on MHD flow of titanium alloy (Ti6Al4V) nanoparticle along with a cross flow and streamwise direction with binary chemical reaction and non-linear radiation: Dual Solutions. J. Mater. Res. Technol. 2019. [CrossRef]

31. Sarafraz, M.M.; Tlili, I.; Tian, Z.; Bakouri, M.; Safaei, M.R.; Goodarzi, M. Thermal evaluation of graphene nanoplatelets nanofluid in a fast-responding HP with the potential use in solar systems in smart cities. Appl. Sci. 2019, 9, 2101. [CrossRef]

32. Suleman, M.; Ramzan, M.; Ahmad, S.; Lu, D.; Muhammad, T.; Chung, J.D. A Numerical Simulation of Silver-Water Nanofluid Flow with Impacts of Newtonian Heating and Homogeneous-Heterogeneous Reactions Past a Nonlinear Stretched Cylinder. Symmetry 2019, 11, 295. [CrossRef]

33. Nnamdi, A.H.; Briggs, T.M.D.; Togunde, O.O.; Obanya, H.E. Antagonistic Effects of Sublethal Concentrations of Certain Mixtures of Metal Oxide Nanoparticles and the Bulk $\left(\mathrm{Al}_{2} \mathrm{O}_{3}, \mathrm{CuO}\right.$, and $\left.\mathrm{SiO}_{2}\right)$ on Gill Histology in Clarias gariepinus. J. Nanotechnol. 2019, 2019, 7686597. [CrossRef]

34. Liu, X.; Tang, J.; Song, B.; Zhen, M.; Wang, L.; Giesy, J.P. Giesy. Exposure to $\mathrm{Al}_{2} \mathrm{O}_{3}$ nanoparticles facilitates conjugative transfer of antibiotic resistance genes from Escherichia coli to Streptomyces. Nanotoxicology 2019, 13, 1422-1436. [CrossRef]

35. Goodarzi, H.; Akbari, O.A.; Sarafraz, M.M.; Karchegani, M.M.; Safaei, M.R.; Shabani, S.; Ahmadi, G. Numerical simulation of natural convection heat transfer of nanofluid with $\mathrm{Cu}, \mathrm{MWCNT}$, and $\mathrm{Al}_{2} \mathrm{O}_{3}$ nanoparticles in a cavity with different aspect ratios. J. Therm. Sci. Eng. Appl. 2019, 11, 061020. [CrossRef]

36. Liao, S. Beyond Perturbation: Introduction to the Homotopy Analysis Method; CRC Press: Boca Raton, FL, USA, 2003.

37. Liao, S. An optimal homotopy-analysis approach for strongly nonlinear differential equations. Commun. Nonlinear Sci. Numer. Simul. 2010, 15, 2003-2016. [CrossRef]

38. Animasaun, I.L.; Ibraheem, R.O.; Mahanthesh, B.; Babatunde, H.A. A meta-analysis on the effects of haphazard motion of tiny/nano-sized particles on the dynamics and other physical properties of some fluids. Chin. J. Phys. 2019, 60, 676-687. [CrossRef]

39. Wakif, A.; Animasaun, I.L.; Satya Narayana, P.V.; Sarojamma, G. Meta-analysis on thermo-migration of tiny/nano-sized particles in the motion of various fluids. Chin. J. Phys. 2019. [CrossRef]

40. Wakif, A.; Boulahia, Z.; Sehaqui, R. Numerical Analysis of the Onset of Longitudinal Convective Rolls in a Porous Medium Saturated by an Electrically Conducting Nanofluid in the Presence of an External Magnetic Field. Results Phys. 2017, 7, 2134-2152. [CrossRef]

41. Amanulla, C.H.; Wakif, A.; Boulahia, Z.; Suryanarayana Reddy, M.; Nagendra, N. Numerical investigations on magnetic field modeling for Carreau non-Newtonian fluid flow past an isothermal sphere. J. Braz. Soc. Mech. Sci. Eng. 2018, 40, 462. [CrossRef]

42. Makinde, O.D.; Omojola, M.T.; Mahanthesh, B.; Alao, F.I.; Adegbie, K.S.; Animasaun, I.L.; Wakif, A.; Sivaraj, R.; Tshehla, M.S. Significance of Buoyancy, Velocity Index and Thickness of an Upper Horizontal Surface of a Paraboloid of Revolution: The Case of Non-Newtonian Carreau Fluid. Defect. Diffus. Forum 2018, 387, 550-561. [CrossRef]

43. Zaib, A.; Khan, U.; Khan, I.; HSeikh, A.; MSherif, E.S. Entropy Generation and Dual Solutions in Mixed Convection Stagnation Point Flow of Micropolar Ti6Al4V Nanoparticle along a Riga Surface. Processes 2020, 8, 14. [CrossRef]

44. Amanulla, C.H.; Saleem, S.; Wakif, A.; AlQarni, M.M. MHD Prandtl fluid flow past an isothermal permeable sphere with slip effects. Case Stud. Therm. Eng. 2019, 14, 100447. [CrossRef] 
45. Qasim, M.; Ali, Z.; Wakif, A.; Boulahia, Z. Numerical Simulation of MHD Peristaltic Flow with Variable Electrical Conductivity and Joule Dissipation Using Generalized Differential Quadrature Method. Commun. Theor. Phys. 2019, 71, 509-518. [CrossRef]

46. Wakif, A.; Boulahia, Z.; Mishra, S.R.; Rashidi, M.M.; Sehaqui, R. Influence of a uniform transverse magnetic field on the thermo-hydrodynamic stability in water-based nanofluids with metallic nanoparticles using the generalized Buongiorno's mathematical model. Eur. Phys. J. Plus 2018, 133, 181. [CrossRef]

47. Zaib, A.; Khan, U.; Shah, Z.; Kumam, P.; Thounthong, P. Optimization of entropy generation in flow of micropolar mixed convective magnetite (Fe3O4) ferroparticle over a vertical plate. Alex. Eng. J. 2019, 58, 1461-1470. [CrossRef]

48. Wakif, A.; Boulahia, Z.; Amine, A.; Animasaun, I.L.; Afridi, M.I.; Qasim, M.; Sehaqui, R. Magneto-Convection of Alumina-Water Nanofluid Within Thin Horizontal Layers Using the Revised Generalized Buongiorno's Model. Front. Heat Mass Transf. 2019, 12. [CrossRef]

49. Wakif, A.; Qasim, M.; Afridi, M.I.; Saleem, S.; Al-Qarni, M.M. Numerical Examination of the Entropic Energy Harvesting in a Magnetohydrodynamic Dissipative Flow of Stokes' Second Problem: Utilization of the Gear-Generalized Differential Quadrature Method. J. Non Equilib. Thermodyn. 2019, 44, 385-403. [CrossRef]

(C) 2020 by the authors. Licensee MDPI, Basel, Switzerland. This article is an open access article distributed under the terms and conditions of the Creative Commons Attribution (CC BY) license (http://creativecommons.org/licenses/by/4.0/). 